\title{
Educación y cultura visual: aportaciones y relaciones necesarias
}

Fernando Miranda ${ }^{1}$

\section{Resumen}

El texto aborda la necesidad de establecer vínculos de ideas entre el desarrollo de la experiencia estética, el enfoque relacional y la perspectiva de la cultura visual, como manera de profundizar la renovación crítica de la educación artística en sus conceptos y en sus prácticas.

Palabras claves: educación; cultura visual; estética relacional

\section{Abstract}

The text addresses the need to establish links between the development ideas of the aesthetic experience, the relational approach and the perspective of visual culture as a way of deepening the renewed criticism of arts education in its concepts and its practices.

Keywords: education, visual culture, relational aesthetics.

\section{Situación de partida en un mundo de imágenes}

No descubriríamos nada si llamáramos la atención sobre la multiplicación de las imágenes en la sociedad contemporánea y sobre las formas en que tales imágenes se muestran, circulan y distribuyen masivamente.

Cientos de imágenes visuales nos rodean cotidianamente, cada vez más sin salir de casa, y aún cada vez más personalmente, a partir de la multiplicación y variedad de artefactos tecnológicos que nos permiten acceder a la visualidad, o quizás con que la visualidad nos accede.

Las imágenes visuales tienen un lugar privilegiado en la contemporaneidad, y muchas veces excluyente, respecto a las formas en que damos significados a nuestro mundo, entendemos lo que nos rodean, aprendemos, nos relacionamos con otras personas, y orientamos nuestras actuaciones personales y colectivas.

La ficción es la realidad cotidiana de acuerdo a los nuevos medios y las tecnologías que modifican definitivamente nuestras maneras de ser y estar en el mundo, y nos obliga a asumir diversidad de personajes en que nos representamos, avatares con que asumimos mostramos a los demás.

Doctor en Educación Artística. Profesor Titular e Investigador del Instituto "Escuela Nacional de Bellas Artes" de la Universidad de la República - Uruguay. 
En este contexto de época, tiempo y espacio se rigen por nuevas coordenadas, la simultaneidad de las relaciones que producimos es ya la manera de vincularnos con otras personas. Probablemente nos encontramos, de manera frecuente, manteniendo diversas conversaciones y contactos al mismo tiempo y transgrediendo los límites espaciales de la realidad material.

Las manifestaciones de la cultura, las creaciones artísticas, los productos estéticos circulan y se distribuyen de formas en que condicionan y orientan definitivamente el armado de la realidad social y subjetiva de los individuos estableciendo preferencias y decisiones, opciones y gustos.

Los clientes del capitalismo actual, en cualquiera de los niveles en que puedan serlo, están llamados a ser los diseñadores aparentes de los productos masivos y la customización del consumo consagra la ilusión de dar nuestro toque de identidad intransferible a la producción globalizada.

El consumo convoca a la masividad pero haciéndolo desde la ilusión de la identidad individual y las señas de las diferencias.

Por esto, lo global se confunde en lo local y aparenta no tener geografía, y la imagen visual muestra las hibridaciones contemporáneas reforzando la idea, en verdad ficción, de pertenencia.

Pero con cuidado debemos advertir que no está en la mera diversidad la condición crítica de la democracia, sino en las búsquedas comunes y colectivas de una mejor vida para todos sin perjuicio de las identidades particulares. No comprender esto significaría perder de vista uno de los que consideramos objetivos fundamentales de la educación artística en el marco de la comprensión de la cultura visual.

Celebrar la diversidad es un festejo apropiado si se sustenta en verdadera participación. La condición de la educación artística en la contemporaneidad podría entenderse también como la apertura de posibilidades para generar nuevos puntos referenciales y sitios de contacto con unas alternativas que contribuyan a desarrollar la experiencia estética y la actuación de las personas. En tal sentido, la diversidad ha de ser, a su vez, el camino del reconocimiento de la experiencia diferente $y$, al mismo tiempo, la oportunidad de conversación y construcción común.

Sin embargo, lo singular, o lo diverso, no puede hacer perder la perspectiva del colectivo 
en el que se desarrollan las personas como sujetos únicos e insustituibles; el sentido de nuestras condiciones de vida debe armarse sobre la base de nuestros auténticos pensamientos, afectos, intereses y deseos.

La alternativa estratégica de un programa que altere el armado hegemónico de las condiciones actuales de la educación artística debe tener, como principio, la efectiva inclusión de la diferencia como identidad y pluralidad, y no como expresión de fragmentos o exclusiones.

Llegados hasta aquí, y a pesar de todo, no es ésta una descripción apocalíptica ni pretende conducirnos a la fatalidad del camino sin opciones. Por el contrario, intentamos mostrar, aún de manera sintética, la necesidad de reconocer nuestros contextos de actuación y pensamiento para producir logros que signifiquen avances y transformaciones en las mejores condiciones de vida de las personas desde lo que la educación artística tenga que ver con esto.

Cabe preguntarnos, entonces, qué condiciones enfrentamos respecto de la nueva situación. Entre otras cosas, y como lo indicara tempranamente José Luis Brea (Las auras frías, 1991), persiste la dificultad dilemática del sentido de lo artístico que se debate entre la diversidad de medios y lenguajes como peligro de disolución de un campo y una práctica específica, y el cumplimiento vanguardista de democratización de lo estético.

Como sostiene Fernando Hernández en referencia directa a las artes visuales:

Estas nuevas miradas se proyectan en las tecnologías (net-art), en la utilización de imágenes de archivo, en una hibridación de géneros y propuestas, debido a que [...] las artes visuales, para la creación de sus representaciones se muestran cada vez más (de)pendientes de la cultura de los medios de comunicación y de las formas de visualidad generadas en la vida cotidiana. (HERNÁNDEZ, 2007:33)

Tal marca de época configura una distinción evidente de las maneras de concebir el arte actual y constituye, en muchos casos, la forma en que cobran mayor relevancia los procesos de producción de la "obra" por sobre la "obra en sí", en ocasiones efímera o intangible.

Pero estas nuevas proyecciones y oportunidades de las tecnologías con su acceso, aplicación y posibilidades generalizadas constituyen, también, parte de la seña de 
identidad de la educación artística.

En cierta forma somos espectadores privilegiados de una redefinición de las prácticas de creación y producción artística que dialoga y discute con el acumulado de la diversidad sedimentada de prácticas anteriores pero que, en cualquier caso, marca una condición de sentido relevante de la situación actual.

En un intento radical por caracterizar tal situación, José Luis Brea dirá que:

No existen 'obras de arte'. Existen un trabajo y unas prácticas que podemos denominar artísticas. Tienen que ver con la producción significante, afectiva y cultural y juegan papeles específicos en relación a los sujetos de la experiencia. Pero no tienen que ver con la producción de objetos particulares, sino únicamente con la impulsión pública de ciertos efectos circulatorios: efectos de significado, efectos simbólicos, efectos intensivos, afectivos... (BREA, 2003: 17)

Arribados a este punto, reconocer las nuevas maneras de la visualidad, junto con las de las prácticas artísticas, es una obligación que debe asumirse en reflexión de los ámbitos diversos de la creación, pero también, de manera más sistemática y constante, en la educación artística.

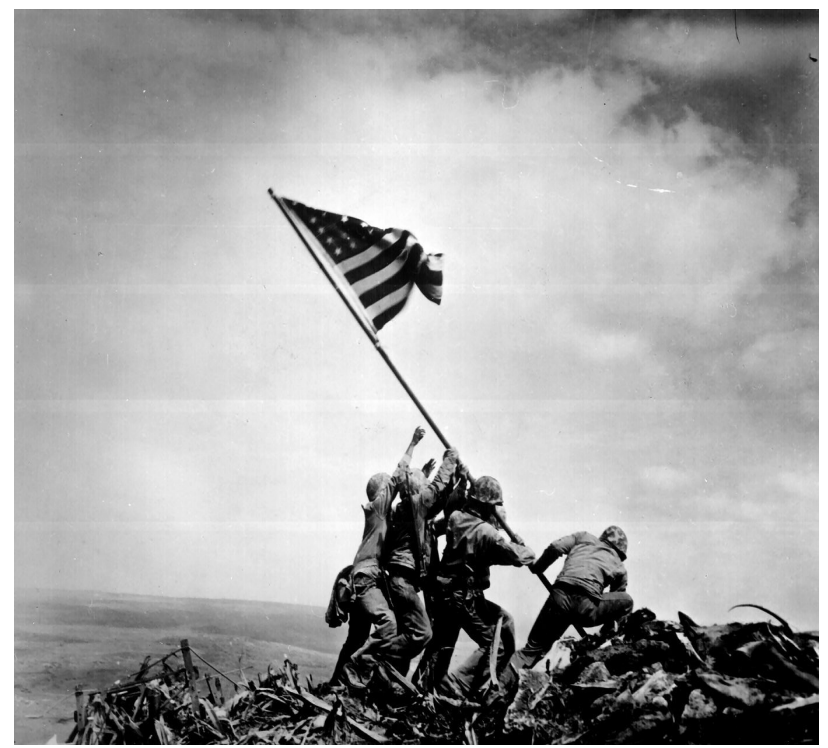

Fotografía de Joe Rosenthal en Iwo Jima (1945) 


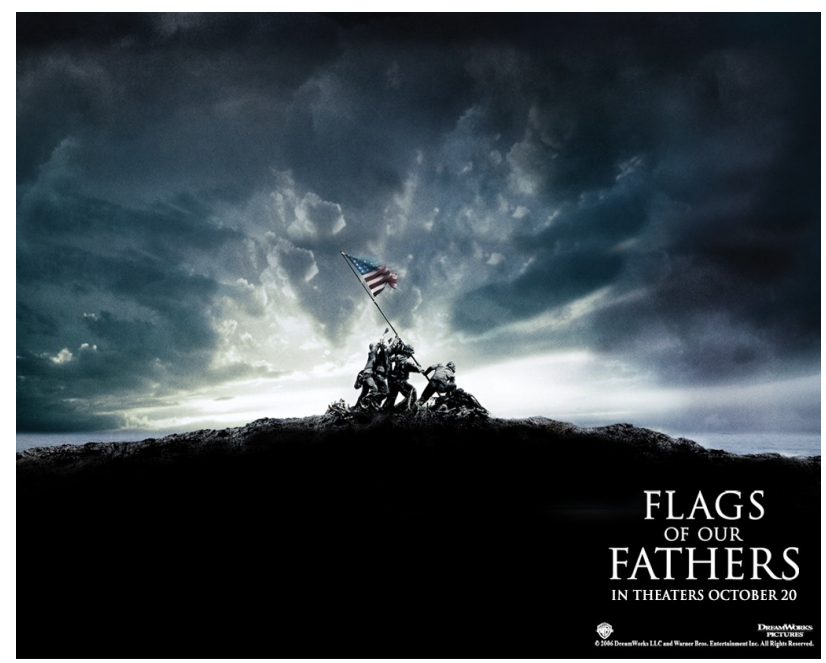

Cartel de promoción del film "Banderas de nuestros padres" (2006)



Publicidad de la compañía Repsol (2009) con la leyenda

"Equipo Repsol. Perseguimos la gloria para compartirla contigo"

Así está montado nuestro escenario, a veces tinglado embarullado y confuso, en que habremos de investigar, producir, pensar, enseñar y lograr que otros encuentren estímulo considerar embarcarse en los desafíos de la educación artística.

\section{De qué se trata la diversidad}

En este contexto contemporáneo, es necesario pensar con responsabilidad las posibilidades de la diversidad en la educación artística desde la comprensión de entorno cultura visual.

La diversidad es una señal de época y debemos utilizar tal condición a favor de los objetivos educativos que nos proponemos, puesto que es ésta una muy interesante 
oportunidad para la producción de saberes y significados.

Lo que quizás sea menos fácil de discernir son las condiciones de tales diferencias en los contextos particulares en que actuamos.

Es decir, una vez considerada la condición de la diferencia como base de la diversidad, como establecer de qué manera ésta se manifiesta en entornos concretos y cercanos; puesto que siempre es más fácil la opinión sobre las diferencias ajenas o en contextos extraños.

¿Cuál es la diversidad que encuentro cotidianamente? ¿Cómo se manifiesta? ¿Cómo me afecta y me involucra? ¿De qué manera represento a los otros, sean estudiantes, colegas, profesores, etc.? ¿Cómo me represento y presento yo mismo? Todas son preguntas que antes que resolverse definitivamente se reformulan continuamente en nuestras prácticas educativas.

Lo que ocurre también, es que la educación artística mantiene más de lo deseado una evidente actuación condicionada por las luchas, conflictos y hegemonías propias del campo de la producción, distribución, exposición y mercado del arte que centra en el artista y su obra como origen y medio de un sentido único de interpretación, significación o disfrute.

Esto no hace más que consolidar un privilegio de relación que conduce a ocultar la diferencia y normalizar lo que debería ser diverso a favor del acceso cultural desde todos los lugares posibles.

El programa de la educación artística a nivel hegemónico puede ser políticamente correcto y aceptado, pero seguramente tendrá escasas consecuencias educativas respecto de la cotidianidad de las personas en las actuales condiciones de época. Culturas subordinadas, subculturas, tribus urbanas, bandas de jóvenes, u otras maneras asociativas, con múltiples creencias, valores, relaciones, y formas de estar individual y colectivamente, son expresiones actuales de la diversidad de personajes que dan casi un tono ficcional a nuestra realidad.

Que nuestras instituciones educativas puedan escandalizarse por algunas de las manifestaciones de lo diverso, cuando hablamos de niños y niñas, y especialmente de adolescentes, no debe ser obstáculo para que una posición crítica nos conduzca a valorar esa tal diversidad en su riqueza de posibilidades. Por tanto, y como no debemos educativa ni éticamente ignorar la condición de la diferencia, asumamos la misma desde 
el desafío de su posibilidad.

Educar desde el marco de la cultura visual es de alguna forma dar sentido y relevancia a los saberes, significados y construcciones simbólicas que representan el mundo para distintas personas y colectivos, de una manera inclusiva, a partir de reconocer la importancia de las maneras de mirar y de los lugares desde los que se ve.

Sea como sea, lo contemporáneo es una condición de época en los distintos espacios sociales que ha modificado las maneras en que se producen las relaciones intersubjetivas, así como las localizaciones reales o virtuales en que aquellas suceden, tanto como sus calidades. Así, la educación artística no puede desatender las nuevas maneras relacionales que la tecnología interpone, sino justamente incorporarlas como posibilidad.

Si coincidimos en que la definición de cultura puede ser asociada a "la instancia en la que cada grupo organiza su identidad" (GARCÍA CANCLINI, 2004:35), pues entonces la educación artística y la particular necesidad de comprensión de la cultura visual debe considerar relevante entender como se producen las identidades actuales locales.

Y si además agregamos a esto que "lo local suele estar en otra parte" (GARCÍA CANCLINI, 2007:87), estaremos en la senda de comprender de qué manera tales identidades localizadas se relacionan, solidarizan e influencian con formas globalizadas. Pero, tan importante como reconocer y analizar los lugares en que lo cultural se hibrida y mezcla de manera diversa, es necesario atender muchas veces estos procesos como reflejo de intereses surgidos de las desigualdades y diferencias sociales y de las relaciones de poder.

El campo cultural y artístico es también un campo de regulación de intereses e intenciones, que buscan, con frecuencia, la conservación de la estructura social, sin dejar de ser, al mismo tiempo, un importante espacio de lucha para la transformación.

La recurrente apelación a la pertenencia cultural, como si esta pudiera ser única y estable, es también una forma institucionalizada en la educación de fijar al sujeto en un lugar determinado desde fuera de su propia capacidad de actuación y construcción de significados.

Como hemos señalado antes, la educación artística debe aproximarse a las personas con las que encamina su acción, mantenerse cerca del conocimiento de éstas. Solo así 
podrá dar destaque suficiente al lugar del otro o de los otros con relación a las construcciones narrativas y de relato que se producen en los contextos educativos siempre múltiples.

A partir de estas definiciones, la ciudad, el barrio, la calle, el colectivo de pertenencia, son espacios privilegiados de intervenciones y manifestaciones visuales que reconocen desde lo comunicacional a lo estético, desde lo mercantil a lo social, desde lo publicitario a lo político.

Lo cultural es territorio simbólico en donde los contrastes, comparaciones y asimilaciones, definirán la negociación entre los diferentes. Pensemos, pues, como construimos la alteridad con identidad sin la pretensión de que ese otro se nos parezca, o permanezca en el lugar que pensé para el o para ella, y detrás de la frontera que le señalamos, aún con la ilusión de protegerlo, como nos mandara la construcción el pensamiento educativo de la modernidad.

Zygmunt Bauman ha de decirnos:

Por mucho que busquemos no encontraremos a nadie que sea exactamente igual a uno mismo. Todos y cada uno de nosotros estamos hechos tan sólo de diferencias. [...] Las diferencias que acaban siendo significativas e importantes a causa de la naturaleza de la frontera, y de las intenciones que hay detrás de esa frontera, son las diferencias atribuidas a las personas que tienen la indecente tendencia a cruzar las fronteras y aparecer por sorpresa en sitios donde no han sido invitados... (BAUMAN, 2006:62-63)

Creemos que para la educación artística, una idea principal es insistir en que la identidad es el desarrollo de una articulación del sujeto con un colectivo social respecto de asumir, y también poder cambiar, una serie de representaciones de significado acerca de cómo se concibe el mundo cotidianamente.

En tales términos, la selección de saberes y contenidos, las orientaciones metodológicas y de práctica, los tipos de relaciones que entablamos con los alumnos y con las personas hacen directamente a la posibilidad de construcción de la identidad cultural y se vinculan con las representaciones, manifestaciones y producciones que concentran elementos visuales de valor simbólico y estético.

Cabe, asimismo, comprender lo estético más allá de la construcción kantiana de la modernidad para ubicarla en el punto de la cotidianidad de las personas y sus relaciones vitales corrientes. 
Tal y como sostiene Paul Duncum para una perspectiva de la cultura visual:

Aesthetics is viewed in site-specific and social terms - in what has become an ordinary language sense of the word as applied to everyday experience as diverse as sport, consumer goods, plastic surgery, television and so on. I argue that adopting this use of aesthetics is particularly useful for those advancing a visual culture approach to art education. (DUNCUM, 2007: s/p)

Para el desarrollo de la acción educativa desde la cultura visual, estas producciones variadas pueden ser referidas a las obras y los lenguajes del arte, a la variedad de formas de la cultura popular, a los mass media, o a cualquier otra manera de representación simbólica como cómics, vídeo clips, expresiones callejeras, graffiti, publicidad, juegos, etc.

En múltiples lugares de representación es posible verificar la mezcla, la hibridación y el contraste con diferentes finalidades y proyecciones.


Publicidad gráfica de automóviles Mitsubishi (2009)

En tal diverso contexto, aquello que definimos incluido en la comprensión de la cultura visual (los acontecimientos visuales producidos a nuestro alrededor $\mathrm{o}$ en condiciones de nuestro acceso, las imágenes con las que nos relacionamos cotidianamente, las variadas tecnologías que soportan esas imágenes, etc.), nos presenta un desafío constante de pensamiento y actuación para entender las relaciones posibles de lo artístico y de lo estético con el saber y la representación. 


\section{Incorporar la relación}

Desde esa misma definición de cultura visual es necesario indagar sobre las maneras de acuerdo, diálogo y disenso con diversas producciones imaginarias y textuales que no pueden circunscribirse a una forma artística ni subordinarse estrictamente a un lenguaje.

En tal sentido, es interesante considerar el aporte de Nicholas Bourriaud (2009) respecto de este punto para asumir la complejidad a la que nos enfrentamos y que anticipamos en puntos anteriores. Dirá Bourriaud:

Una performance de Vito Acconci hecha en 1970, de la que sólo subsistiría una documentación fotográfica y testimonios, representa potencialmente el mismo valor que una escultura expuesta en las salas de un museo -en este caso, el valor de una partitura que se puede volver a tocar, pero también la de un acontecimiento artístico cuya onda expansiva no se reduce para nada a su duración física. (BOURRIAUD, 2009:96)

Transformar desde la condición contemporánea debe incluir considerar las posibilidades de la época y ser realizado desde sus señas particulares, que incluyen entender unas reglas de juego que debemos conocer.

Zygmunt Bauman dirá: "La proximidad virtual pode ser interrumpida, literal y metafóricamente a la vez, con sólo apretar un botón." (BAUMAN, 2005:88) Pero, al mismo tiempo, la tecnología permite un sistema de relaciones e intercambios que la materialidad ve, a esta altura, limitada.

Estos espacios cada vez más definen la construcción de lo cultural, de lo simbólico, de lo estético, de lo artístico, del diseño: en suma, de las condiciones de la visualidad de época. Por tanto, son a la vez espacios en los que el mundo es representado y en los que adquiere sus significaciones cotidianas.

No podemos responsabilizar a las nuevas tecnologías ni a la digitalización de lo cotidiano por todo lo que nos sucede, sino más bien asumir cuáles son los desafíos que representan en esta nueva realidad y cuáles de ellos, a su vez, corresponden a la educación artística y a la investigación en cultura visual.

Volvamos a Bourriaud:

La producción cultural constituye pues una caída permanente de 
objetos visuales, sonoros, escritos, representados, de calidad desigual y de estatutos heterogéneos, de la que el lectorespectador recoge lo que puede, con los medios de los que dispone según su educación, su bagaje intelectual y su carácter. ¿Qué hacer entonces cuando a uno le cae esta lluvia encima? (BOURRIAUD, 2009: 167)

Por eso, las prácticas culturales, artísticas y sociales, pero especialmente las prácticas educativas, requieren ser localizadas, realizadas por colectivos definidos en torno a pertenencias identitarias y condiciones particulares de contextos, necesitan también constituirse en la posibilidad de la relación y la crítica como condición de visibilidad y producción de significados.

Esto es, considerar "qué tiene que ver conmigo" -con nosotros- aquello que pasa en nuestro entorno cultural para generar a partir de allí una acción real crítica sobre los entornos cotidianos, interponiendo de nuevas prácticas y posibilidades de pensamiento.

La condición pedagógica del arte y la cultura visual para contraponer a lo que Giroux (2004) definiría como el incremento de espacios hipercomercializados (hypercommercialized spaces) no puede radicarse exclusivamente en las instituciones educativas, aunque si deba incluirlas de manera fundamental. Por esto es necesario recuperar espacios sociales de actuación pública (reales o virtuales) que permitan recolocar en ámbitos de acceso colectivo aquello que muchas veces se ha resignado hacia lo mercantil, lo institucional, lo estatal, o lo privado.



Publicidad de pan "Bimbo" en la Rambla de Montevideo (2008) 


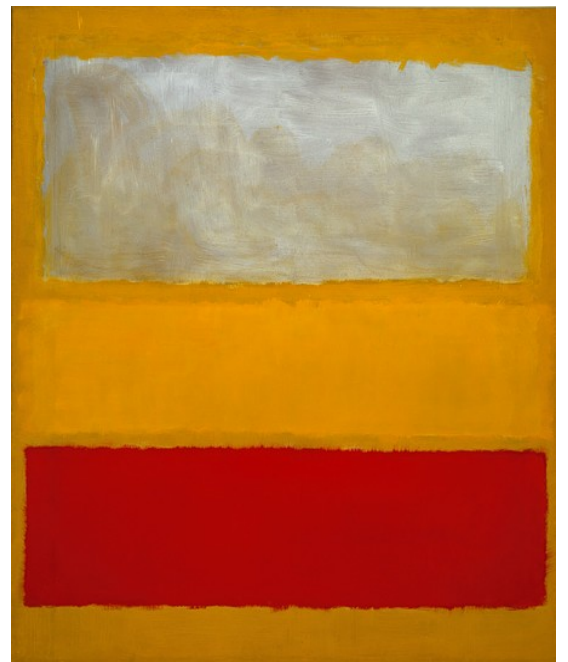

Marc Rothko

White, Red on Yellow (1958)

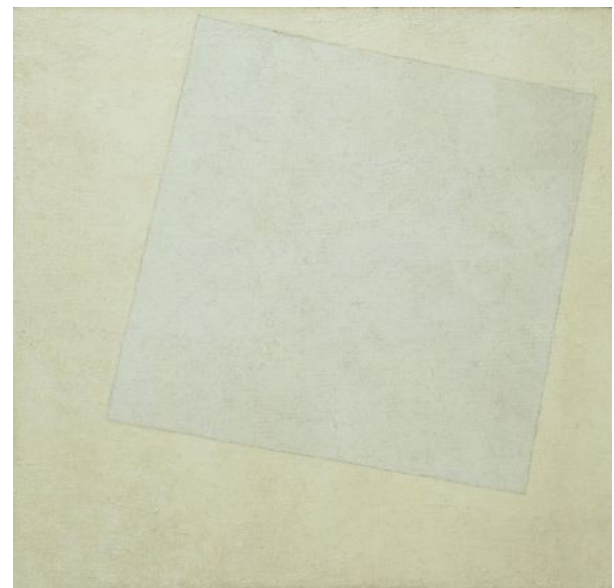

Kazimir Malevich

Cuadrado blanco sobre fondo blanco (1918)

El objetivo debe ser convocar a las personas (los visualizadores, tal como seguramente diría Fernando Hernández (2007) -alumnos y profesores, en primera instancia- a constituirse en creadores de significado, en productores de sentido respecto de la visualidad.

Nuestro programa implica reconocer de qué manera las imágenes se relacionan con la producción de la experiencia estética y los acontecimientos educativos desde un punto de vista relacional y partiendo de aquellas referencias con que las personas construyen su mundo y le dan sentido y significado.

Atender esta situación es establecer la relación entre la educación artística y la cultura visual donde la imagen como enunciado de discurso va más allá de su formalidad visible y de la intención de su productor.

Entonces, es allí donde se hacen importantes las biografías de las personas que utilizan de una u otra manera las imágenes como medio de significación, representación, y comunicación. No hay una forma de visualización única y probada salvo que nos posicionemos en construcciones canónicas que ya es necesario abandonar. Así, pensar en términos de cultura visual

proporciona, de forma inherente, el contexto para las artes visuales en sus efectos y destaca las conexiones entre las formas del arte popular y las bellas artes. (FREEDMAN, 2006:25) 
En nuestra experiencia hemos comprobado la necesidad de crear nuevas maneras relacionales que generen acontecimientos educativos y estéticos respecto de lo visual y hemos visto también como los significados se reformulan cada vez respecto del punto de mirada de los otros. Hemos podido, en muchas ocasiones y aún con éxitos y decepciones, "hacer de las artes, como en general de todo el conocimiento, un ámbito donde recrear, poner a prueba y representar experiencias de vida". (AGIRRE, 2008:15)

En este cruce es donde se ubica el valor de la educación artística y de la Cultura Visual como lugar de intersección de saberes, aquello que Freedman definiría como el espacio "de pensamiento dentro del cual existe la práctica que tiene que ver con qué, por qué, y cómo llegamos a tener conocimiento sobre la cultura visual".(FREEDMAN, 2006:33)

De aquí que consideramos que la perspectiva relacional tiene mucho que aportar a la educación artística y a la cultura visual en tanto es básico:

...tomar conciencia de los modos de producción y de las relaciones humanas producidas por las técnicas de su época. El arte hace mucho más visibles esos modos de producción, dándonos la posibilidad de imaginar incluso sus consecuencias en la vida cotidiana. (BOURRIAUD, 2006:82)

Es en estos procesos donde la educación artística desde la perspectiva de la cultura visual ha de interesarse particularmente llevando nuestro propia acción de educadores y de ciudadanos más allá de la evidencia aparente.

Lo fundamental, además, es que tal acción contenga un sentido de agencia que permita explicar las maneras subjetivas y compartidas de ver el mundo, comprenderlo y actuar para crear realidades posibles.

\section{Referencias}

AGIRRE, Imanol "Culturas juveniles y ambientes escolares" en Lucina Jiménez; Imanol Aguirre y Lucia G. Pimentel (coord.): Educación artística, cultura y ciudadanía (2009): Madrid: OEI - Fundación Santillana.

AGIRRE, Imanol: "Contenidos y enfoques metodológicos de la educación artística", Observatorio Laboratorio de Investigación Creación, 2008. Disponible en http://enobserva.wordpress.com/?s=Imanol 
BAUMAN, Zygmunt (2006): Confianza y temor en la ciudad. Vivir con extranjeros. Barcelona: Arcadia

BAUMAN, Zygmunt (2005): Amor líquido. Madrid: Fondo de Cultura Económica

BOURRIAUD, Nicholas (2009): Radicante. Buenos Aires: Adriana Hidalgo

BOURRIAUD, Nicholas (2006): Estética Relacional. Buenos Aires: Adriana Hidalgo editora

BREA, José Luis (2003): El tercer umbral. Estatuto de las prácticas artísticas en la era del capitalismo cultural. Murcia: CENDEAC

BREA, José Luis (2002): La era postmedia. Salamanca: Editorial Centro de Arte de Salamanca

BREA, José Luis (1991): Las auras frías. Barcelona: Anagrama

DUNCUM, Paul, "Aesthetics, Popular Visual Culture, and Designer Capitalism" en Journal of Art \& Design Education. 26.3 (2007) (285-295)

FREEDMAN, Kerry (2006): Enseñar la cultura visual. Currículum, estética y la vida social del arte. Barcelona: Octaedro

GARCÍA CANCLINI, Néstor (2007): Lectores, espectadores e internautas. Barcelona: Gedisa

GARCÍA CANCLINI, Néstor (2004): Diferentes, Desiguales y Desconectados. Barcelona: Gedisa

GIROUX, Henry. A. (2004): The Abandoned Generation Democracy Beyond the culture of fear. New York: Palgrave Macmillan

GIROUX, Henry. A. (2001): Cultura, política y práctica educativa. Barcelona: Graó

HERNÁNDEZ, Fernando (2007): Espigador@s de la cultura visual. Otra narrativa para la educación de las artes visuales. Barcelona: Octaedro 
HERNÁNDEZ, Fernando, "Culturas juveniles, prácticas de subjetivización y educación escolar" en Andalucía Educativa, 46, 22-24 (2004) (disponible en: http://www.cecace.org/docs/Culturas_juveniles.pdf)

HERNÁNDEZ, Fernando (2000): Educación y Cultura Visual. Barcelona: Octaedro 